ERNEST DRLANDUAWRENEE B ERKELEY NATIONAL LABGRATDRY

\title{
Reducing Mortality from Terrorist Releases of Chemical and Biological Agents: I. Filtration for Ventilation Systems in Commercial Buildings
}

Tracy L. Thatcher and Joan M. Daisey

Environmental Energy

Technologies Division

September 1999

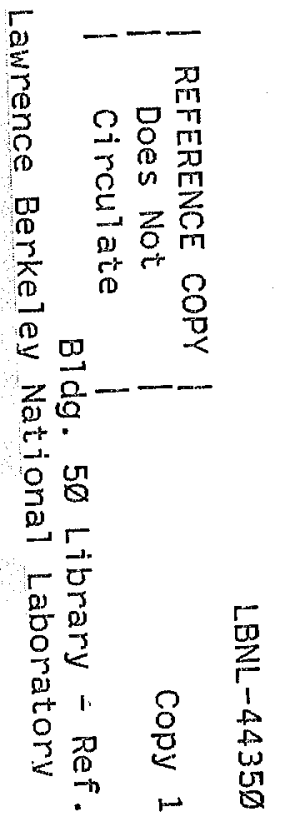




\section{DISCLAIMER}

This document was prepared as an account of work sponsored by the United States Government. While this document is believed to contain correct information, neither the United States Government nor any agency thereof, nor The Regents of the University of California, nor any of their employees, makes any warranty, express or implied, or assumes any legal responsibility for the accuracy, completeness, or usefulness of any information, apparatus, product, or process disclosed, or represents that its use would not infringe privately owned rights. Reference herein to any specific commercial product, process, or service by its trade name, trademark, manufacturer, or otherwise, does not necessarily constitute or imply its endorsement, recommendation, or favoring by the United States Government or any agency thereof, or The Regents of the University of California. The views and opinions of authors expressed herein do not necessarily state or reflect those of the United States Government or any agency thercof, or The Regents of the University of California.

Encst Orlando Lawrence Berkeley National Laboratory is an equal opportunity employer. 
LBNL-44350

\title{
Reducing Mortality from Terrorist Releases of Chemical and Biological Agents: I. Filtration for Ventilation Systems in Commercial Buildings
}

\author{
Tracy L. Thatcher and Joan M. Daisey
}

Environmental Energy Technologies Division

\author{
Ernest Orlando Lawrence Berkeley National Laboratory \\ University of California \\ Berkeley, California 94720
}

September 1999

This work was supported by the Office of Research and Development, Office of Nonproliferation and National Security, of the U.S. Department of Energy under Contract No. DE-AC03-76SF00098. 
(8) rayclod paper 


\section{Table of Contents}

Page

ABSTRACT $\quad$ ii

Acknowledgements

1. INTRODUCTION 1

2. PHYSICAL NATURE OF CHEMICAL AND BIOLOGICAL AGENTS 2

3. PARTICLE REMOVAL FROM AIR BY FILTRATION 2

4. VAPOR REMOVAL 6

5. PROTECTION SYSTEM DESIGN 9

6. PRESSURE DROP 11

7. DESIGN CASE STUDY 11

Option 1. Multi-Unit Design 12

Option 2. Pleated Filter Holder Design $\quad 14$

8. SUMMARY AND CONCLUSIONS 15

9. REFERENCES 16

$\begin{array}{ll}\text { Appendix } & 18\end{array}$ 



\begin{abstract}
There is growing concern about potential terrorist attacks involving releases of chemical and/or biological (CB) agents, such as sarin or anthrax, in and around buildings. For an external release, the CB agent can enter the building through the air intakes of a building's mechanical ventilation system and by infiltration through the building envelope. For an interior release in a single room, the mechanical ventilation system, which often recirculates some fraction of the air within a building, may distribute the released $\mathrm{CB}$ agent throughout the building. For both cases, installing building systems that remove chemical and biological agents may be the most effective way to protect building occupants. Filtration systems installed in the heating, ventilating and airconditioning (HVAC) systems of buildings can significantly reduce exposures of building occupants in the event of a release, whether the release is outdoors or indoors. Reduced exposures can reduce the number of deaths from a terrorist attack.

The purpose of this report is to provide information and examples of the design of filtration systems to help building engineers retrofit HVAC systems. The report also provides background information on the physical nature of $\mathrm{CB}$ agents and brief overviews of the basic principles of particle and vapor filtration.
\end{abstract}





\section{Acknowledgements}

This work was supported by the Office of Research and Development, Office of Nonproliferation and National Security, U.S. Department of Energy under Contract No.DE-AC03-76SF00098. The authors thank W. W. Delp, W. J. Fisk, and W. F. Tschudi for their review of this report and thoughtful comments. 



\section{INTRODUCTION}

There is growing concern about potential terrorist attacks involving releases of chemical and/or biological (CB) agents, such as sarin or anthrax, in and around buildings. ${ }^{1}$ Two basic scenarios exist for the exposure of building occupants to $\mathrm{CB}$ agents: a release of the CB agent outside of the building or a release within the building. For an external release, the $\mathrm{CB}$ agent can enter the building through the air intakes of a building's mechanical ventilation system and by infiltration through the building envelope. For an interior release in a single room, the mechanical ventilation system, which often recirculates some fraction of the air within a building, may distribute the released CB agent throughout the building.

Ideally, building occupants would be evacuated to a safe distance in the event of a $\mathrm{CB}$ attack. However, once a release has occurred, this may not be possible. For moderate winds of $10 \mathrm{mph}$, an outdoor plume will travel one mile in about 6 minutes, making evacuation in an urban area impractical. Additionally, since the health effects of biological agents are delayed, an attack may not even be detected when it occurs. Therefore, installing filtration systems that remove chemical and biological agents may be the most effective way to protect building occupants. Filtration systems installed in the heating, ventilating and air-conditioning (HVAC) systems of buildings can significantly reduce exposures of building occupants in the event of a release, whether the release is outdoors or indoors. Reduced exposures can reduce the number of deaths from a terrorist attack. Filtration also aids in post-event clean-up by reducing the extent and spread of contamination. However, this protection is not without cost and requires additional capital investment, more space for the HVAC system, and increased energy consumption on an ongoing basis.

\section{Other Benefits of HVAC Filtration}

Improved filtration systems may provide additional benefits for building occupants and owners on a day-to-day basis. Reductions in airborne particles which deposit and soil indoor surfaces can decrease cleaning needs and reduce some types of electronic equipment failures which are due to particle deposition on circuitry. Circulation of cold and flu viruses and of some allergens will also be reduced, although whether this reduction would provide a health benefit is not known.

The purposes of this report are to provide:

1. Background on the physical nature of $\mathrm{CB}$ agents (section 2);

2. Brief overviews of the basic principles of particle (section 3) and vapor (section 4) filtration;

\footnotetext{
${ }^{1}$ This report addresses non-residential urban buildings, such as offices, etc., which are equipped with mechanical ventilation systems.
} 
3. Information and sample calculations to illustrate the viability of retrofitting HVAC systems with filtration to remove $\mathrm{CB}$ agents from air (sections 5 and 6).

\section{PHYSICAL NATURE OF CHEMICAL AND BIOLOGICAL AGENTS}

The agents of concern in terrorist attacks are generally classified into two major categories: (1) chemical agents, and (2) biological agents. Regardless of category, the agent must be dispersed in air by some means in order to come into contact with the building occupants either through inhalation or dermal contact. If it remains in some container, it will not come into contact with building occupants, i.e., there will be no exposures.

The chemical agents (such as phosgene, sarin, or adamsite) may be gases, liquids or solids at typical indoor conditions, depending upon their molecular formulas. Chemical agents that are gases and vapors exist as single molecules dispersed in air. Chemical agents that are liquids may be dispersed as vapors and/or aerosols (particles or droplets suspended in air). If a chemical agent is dispersed as an aerosol, then each particle contains an aggregate of many molecules, sometimes mixed with other chemicals. Liquid chemical agents initially dispersed as an aerosol may volatilize over time to give a mixture of vapor and droplet forms. Chemical agents that are solids, such as Adamsite and phosgene oxime, would also be dispersed as aerosols. The median sizes of the dispersed particles can vary considerably, ranging from about $0.1 \mu \mathrm{m}$ to as large as about $100 \mu \mathrm{m}$, depending upon the method used for generation and dispersion.

Particles and gases exhibit different physical behavior and must be removed from air by different types of filtration systems. Fiber filters are commonly used to remove particles from intake and recirculated air in HVAC systems. Fiber filter systems have a long history of use in building systems and their long term behavior in HVAC systems is well known. However, fiber filters are ineffective for removing gases and vapors. For removing non-particulate contaminants, charcoal filters are useful for a wide range of organic species. Although charcoal filtration is currently used in building HVAC systems for some specialty applications, it is not common in typical HVAC systems and has a much shorter history of use in buildings than fiber filters.

Biological warfare agents may consist of a toxin (a single chemical) from a biological source (e.g., botulinum toxin), a bacterial organism, (e.g., anthrax), a fungal agent (e.g., Valley fever), a rickettsia (e.g., typhus) or a viral organism (e.g., dengue fever). In general, these agents are more toxic per unit mass than the chemical agents. The biological agents are particulate (aerosols) in nature, with sizes that vary widely, depending upon the specific agent (See Figure 1). The actual size of the bioaerosol released in a terrorist attack will also depend upon the method of dispersion. When released as single organisms, the aerosol size would equal the organism size shown in Figure 1. However, in many instances the agent will be released in a carrier fluid or as a multi-organism "clump". Under these circumstance the size of the agent aerosol could be considerably larger than the organism size. Since the biological agents are particles, they can be removed from air using particle filters. 


\section{PARTICLE REMOVAL FROM AIR BY FILTRATION}

The amount of a bioaerosol or chemical aerosol that can be removed from the air by an HVAC particle filtration system depends upon a number of factors, including whether the release is outside or inside of the building, the type and placement of the filter within the HVAC system, the rate of air flow through the filter, air leakage past the filter, and the size of the particles to be removed. If the release is in outdoor air, then all of the outside air brought in via the HVAC

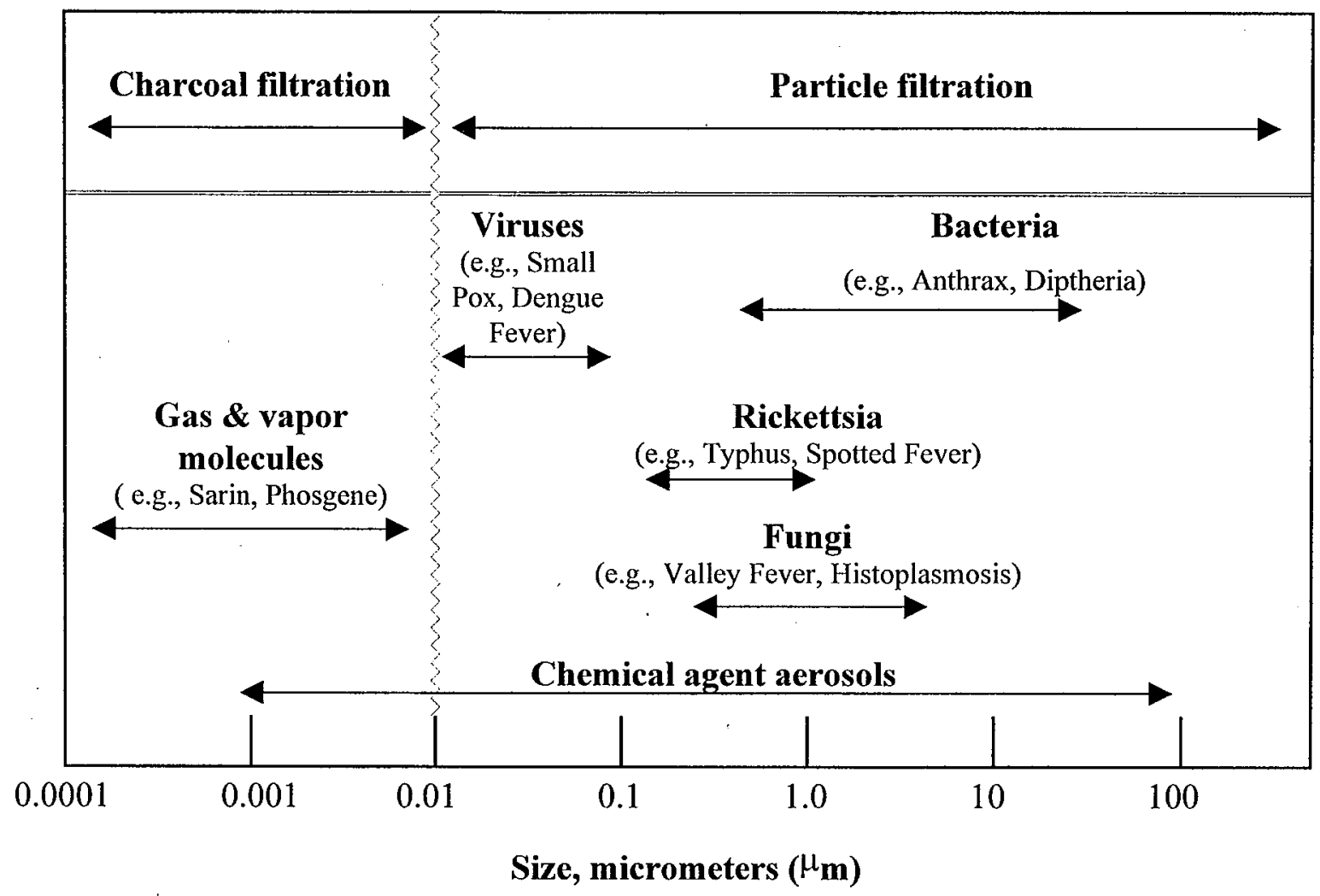

Figure 1. Approximate Sizes of Chemical and Biological Warfare Agents. $1 \mu \mathrm{m}=0.00004$ inches

system can be filtered. If the release is indoors and some fraction of the indoor air is recirculated (as is common during heating and cooling seasons), then the recirculated air can be filtered before it is redistributed to other parts of the building, thus reducing agent spreading and exposures.

The particle removal efficiency for any given filter is highly dependent upon the type of filter, the sizes of the particles being removed, and the velocity of air passing through the filter. The filter efficiency rating is very dependent upon the method used to test the filter. For in-duct particle filters used in HVAC systems, filtration efficiency is most commonly based on the standardized test methods in ASHRAE Standard 52.1 (1992). 
The ASHRAE Weight Arrestance (gravimetric) test measures the percentage of the mass of a test aerosol removed by the tested filter initially and on average over a specified time. The average of the weight arrestance is very commonly used as a measure of the filtration efficiency of commercial filters. Since the test aerosol used is dominated by large (coarse) particles, this efficiency measurement does not provide adequate information on removal efficiency for smaller particles in the 0.1 to 1 um range.

The ASHRAE Atmospheric Dust Spot Efficiency rating is based on the relative discoloration by ambient (outdoor air) aerosol of sample filters placed upstream and downstream of the test filter. Although the results of this test are weighted slightly more toward smaller particles, this filter efficiency rating method does not directly yield efficiency as a function of particle sizes.

In the research community, filter particle removal efficiency is commonly determined as a function of particle size. Since particles in the size range of about 0.1 to $0.3 \mu \mathrm{m}$ are the most difficult to remove by filtration, the minimum filter efficiency is often reported for particles in this size range. The removal efficiency for both larger $(>0.3 \mu \mathrm{m})$ and smaller $(<0.1 \mu \mathrm{m})$ particles will always be greater than this efficiency rating value. ASHRAE is currently in the process of developing a standardized test for fractional filtration efficiency, i.e., filtration efficiency as a function of particle size.

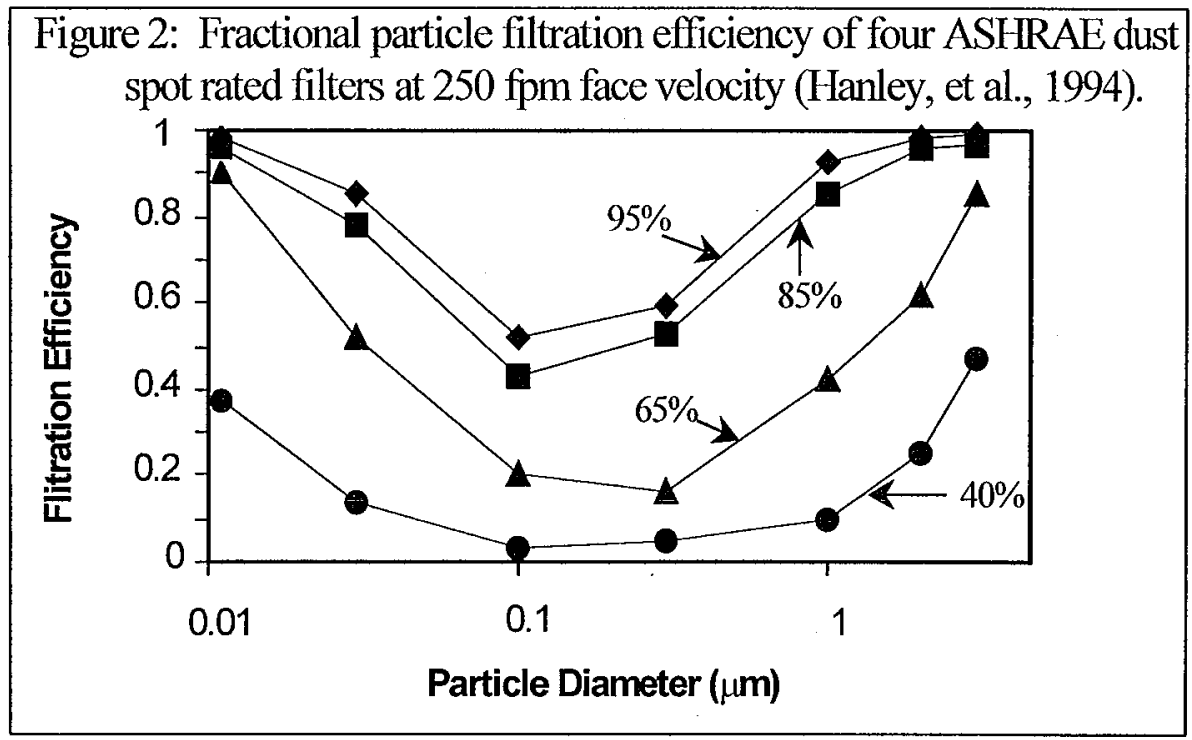

There are only limited data to allow a comparison of the ASHRAE dust spot filter ratings to filtration efficiency as a function of particle size. Hanley, et al. (1994) conducted experiments to determine the particle filtration efficiency of four pleated paper media filters used for HVAC systems in commercial buildings as a function of particle size. Figure 2 reproduces the data of Hanley, et al. (1994) showing the particle filtration efficiency at $250 \mathrm{fpm}$ face velocity of four ASHRAE rated filters, which had dust spot efficiencies of $95 \%, 85 \%, 65 \%$, and $40 \%$. These efficiency curves are for new filters. As filters become loaded with particles, removal efficiencies typically increase. Although the exact filtration efficiencies shown in Figure 2 are valid only for the particular filters tested (pleated paper-media filters) and at the given face 
velocity, they illustrate two important principles which must be understood in order to design an effective filtration system. First, the results show the relationship between filtration efficiency and particle size discussed above, with a minimum efficiency occurring for particle diameters between about 0.1 and $0.3 \mu \mathrm{m}$. Second, it is not correct to interpret the ASHRAE filter efficiency ratings based on mass arrestance or dust spot as the removal efficiency for all particle sizes. The filtration efficiencies for particles between 0.1 and 0.5 micron in diameter were all significantly below the efficiency indicated by the ASHRAE rating. For example, the ASHRAE $95 \%$ average dust spot efficiency rated filter (Figure 2) removes just over $50 \%$ of incoming 0.1 $\mu \mathrm{m}$ particles. In contrast, High Efficiency Particulate Absolute (HEPA) filters are rated according to their ability to remove $0.3 \mu \mathrm{m}$ particles, typically $99.9 \%$ removal or better, and would be expected to remove all other sizes of particles at or above the rated efficiency.

Air velocity through the filter also affects particle removal efficiency. In general, particle filtration efficiency decreases with increasing velocity through the filter. For the $85 \%$ ASHRAE rated pleated paper-media filter tested by Hanley, et al. (1994), increasing the face velocity of the air moving through the filter from $130 \mathrm{fpm}$ to $440 \mathrm{fpm}$ decreased the filtration efficiency for 0.1 $\mu \mathrm{m}$ diameter particles from about $50 \%$ to about $38 \%$.

The variation of filtration efficiency with particle diameter underscores the importance of considering the diameter of the particles to be removed when designing a filtration system for $\mathrm{CB}$ agent removal. For agents which form spores (such as Anthrax and Valley Fever) and most bacteria (such as Diptheria), the particle sizes encountered would be larger than a micron and would be filtered well by filters with a moderate to high ASHRAE dust spot rating. However, Rickettsia (such as Spotted Fever and Typhus) are in the 0.2 to $1 \mu \mathrm{m}$ size range and the smaller rickettsia would be removed poorly by even 95\% ASHRAE dust spot filters if they were dispersed as individual organisms. Viruses (such as Small Pox or Yellow Fever) exist as very small particles, typically 0.01 to $0.03 \mu \mathrm{m}$, and many can be freeze dried to allow them to persist for long periods. If these particles were dispersed individually, they are so small that they would be captured with reasonable efficiency by any high quality ASHRAE rated filter. However, an attack that was designed to have maximum penetration through filtration systems would disperse viruses in a carrier or in clumps that would have diameters in the 0.1 to 0.3 micron range, which are much more difficult to remove. The particle size for solid chemical agents (such as Adamsite and phosgene oxime) and biotoxins (such as Botulinus and Ricin) depends on the method used to prepare the powder before dispersal. It would be difficult, although not impossible, to disperse these agents as submicron particles.

Since some biological and chemical agents can be dispersed in particle size ranges that are difficult to remove, the most complete protection would be afforded by a system using HEPA quality filters. Although 95\% ASHRAE rated filters can provide good protection against some biological agents, they provide only $50 \%$ removal for 0.1 to $0.3 \mu \mathrm{m}$ particles. A well designed attack using viruses, rickettsia, biotoxins, or solid chemical agents could significantly penetrate these filters, increasing exposure and casualties. The level of protection required and therefore the type of filter chosen, will depend on the sensitivity of the building and the likelihood of attack. Those buildings which are at particular risk of being targeted by a well organized terrorist organization may choose a higher level of filtration efficiency, despite the added costs involved. 
However, for buildings determined to be under a less specific threat, a filter with a high dust spot rating will afford adequate protection from all but the most sophisticated attack.

As a practical matter, to ensure the efficiency of an installed filter, it is extremely important to install the filter properly and to make sure that there is no air leakage around the filter frame. In a typical filter installation, some portion of the air will pass around the filter, leaking around the filter frame and holder. If $10 \%$ of the air in a system bypasses the filter, a filter which removes $99.9 \%$ of the particles passing through it will result in a system efficiency of only $90 \%$ since the particle concentration in air which bypasses the filter is essentially unreduced. Therefore, leak sealing within a CB agent protection system needs to exceed the level required in a standard HVAC system in order to get the full benefit of the increase in filter quality. To assure the integrity of the system, these seals need to be tested after installation and rechecked periodically.

\section{VAPOR REMOVAL}

Although particle filters can remove airborne droplets of liquid chemical agents, in most cases these captured droplets will evaporate from the filter into the airstream and lead to chemical agent vapors entering the building. Because of this evaporation, particle filters provide essentially no protection from chemical agent droplets or gases. In order to protect buildings from these agents, an additional treatment system is required. The goal of this treatment system is to protect against a broad spectrum of chemical agents. The treatment method that provides the best protection over the broadest range of agents is adsorption onto impregnated activated carbon. Treatments such as hydrolysis and UV oxidation, which provide effective removal of some agents and little or no removal of others, are less desirable than a more broadly effective method.

Activated carbon is a good adsorbent for high molecular weight non-polar and slightly polar chemicals in the vapor phase. In practice, this means that most organic molecules, such as nerve gases, adsorb well onto activated carbon, with low volatility chemicals adsorbing better than highly volatile chemicals. Since adsorption is a surface phenomenon, the three most important features for determining a particular carbon's effectiveness are (1) surface area, which influences the total mass of chemical vapor that can be adsorbed, (2) pore structure, which influences the speed with which the chemical contaminant can be adsorbed at the surfaces and to some extent what can be adsorbed, and (3) granule size, which will affect both the adsorption rate and the pressure drop through the filter.

Activated carbon alone does not provide protection against some common chemical agents. In order to remedy this problem, chemical agent respirators use activated carbon impregnated with a mixture of metals (which act as an acid gas sink) and triethylenediamine (TEDA). These additives aid in the removal of agents that are not readily adsorbed onto un-impregnated activated carbon, such as cyanogen chloride (CK), phosgene (CG), and hydrogen cyanide (AC). It is important to recognize that the impregnation materials reduce the available carbon surface area and somewhat reduce the adsorption capacity of the carbon for other chemical agents. 
However, without impregnation, an activated carbon treatment system will be ineffective against some chemical agents, leaving the building vulnerable to attacks using these agents.

The adsorption capacity of activated carbon for chemical vapors is dependent on many factors including the carbon type, specific chemical agent, agent concentration, and relative humidity. Since the capacity of carbon to adsorb organic chemicals tends to decrease with increasing volatility, sizing the system to adsorb the most volatile chemical agent will provide a conservative design. Since sarin is the most volatile nerve agent, we will design using sarin as the assumed agent.

The highest chemical vapor concentrations would most likely occur for a release of droplets of sarin which are captured by the particle pre-filter(s) installed upstream of the carbon filters and then volatilize from the filter surface. Air fully saturated with sarin at $20{ }^{\circ} \mathrm{C}$ would contain approximately $24 \mathrm{~g} / \mathrm{m}^{3}$. Full saturation is highly unlikely but provides a basis for the most conservative estimate of the amount of carbon needed for an effective system. Figure 3 shows the mass of agent adsorbed before breakthrough by $12 / 30$ mesh ( 0.6 to $1.4 \mathrm{~mm}$ diameter carbon grains) and 4/10 mesh (1.6 to $4.7 \mathrm{~mm}$ ) carbon over a range of chemical agent (sarin, in this case) concentrations, velocities through the carbon bed, and bed depths. Breakthrough is defined as the time when the concentration exiting the carbon bed is equal to the 8 hour, time-weighted average (TWA) concentration limit established for health protection of munitions workers $\left(0.0001 \mathrm{mg} / \mathrm{m}^{3}\right)$. The breakthrough calculations include both the speed at which a contaminant is adsorbed and the total capacity of the bed. Although the system will continue to remove agent after the breakthrough point, the undiluted outlet concentration will no longer be safe for breathing. In order to assure that a well designed system could achieve these removals, the values in Figure 3 were calculated using conservative assumptions. The detailed equations and assumptions are provided in the appendix of this report. Due to limited data, the effect of inlet agent concentration on the adsorption capacity of the carbon was not taken into account. If we extrapolate from the volatile organic chemical data of Nelson and Correia (1976), we can estimate that at high concentrations agent adsorption could be as much as twice the value predicted in Figure 3. However, at the lowest concentrations, the total amount removed would be slightly lower. The calculations in this report assume the use of high grade impregnated activated carbon, with adsorption characteristics that are at least equivalent to those of military grade respirator carbon.

In addition to carbon adsorption capacity, the adsorption rate within the carbon bed must be considered. Since adsorption is not an instantaneous process, the agent concentration within the carbon bed will decrease from the incoming concentration to zero over a flow distance called the transfer zone. The length of this zone will depend on variables such as the air flow rate through the carbon bed, initial agent concentration, carbon pore structure, and carbon grain size. If the transfer zone is longer than the carbon bed depth, some agent will pass through the bed immediately, even though the capacity of the bed has not been reached. The effect of the transfer zone on adsorption can be most easily seen when looking at the effect of bed depth on adsorption in Figure 3. For instance, for $4 / 10$ mesh carbon (velocity $50 \mathrm{fpm}$, sarin concentration $24 \mathrm{~g} / \mathrm{m}^{3}$ ) a 1 inch deep bed adsorbs $47 \mathrm{~g}$ per square foot of filter area. However, under the same conditions 
Figure 3a: Sarin Adsorption Capacity of 4/10 Mesh Activated Carbon'

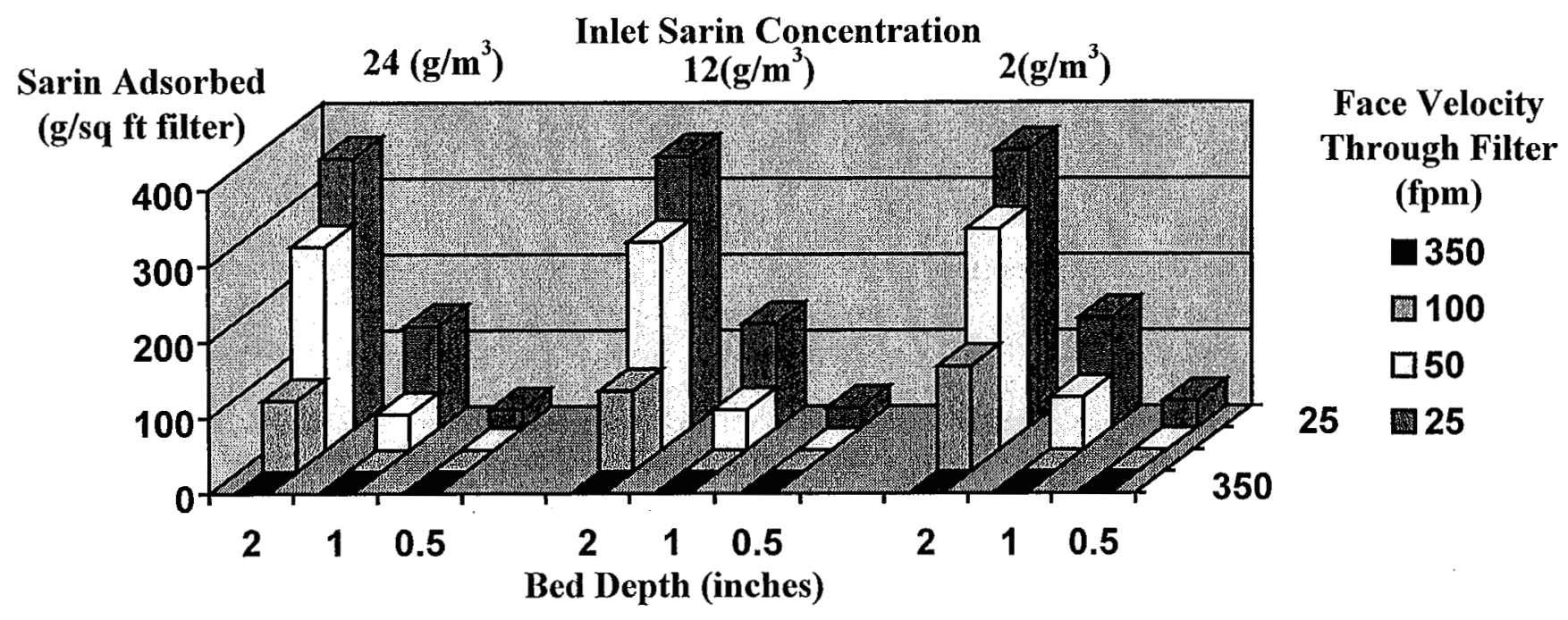

Figure 3b: Sarin Adsorption Capacity of 12/30 Mesh Activated Carbon ${ }^{1}$

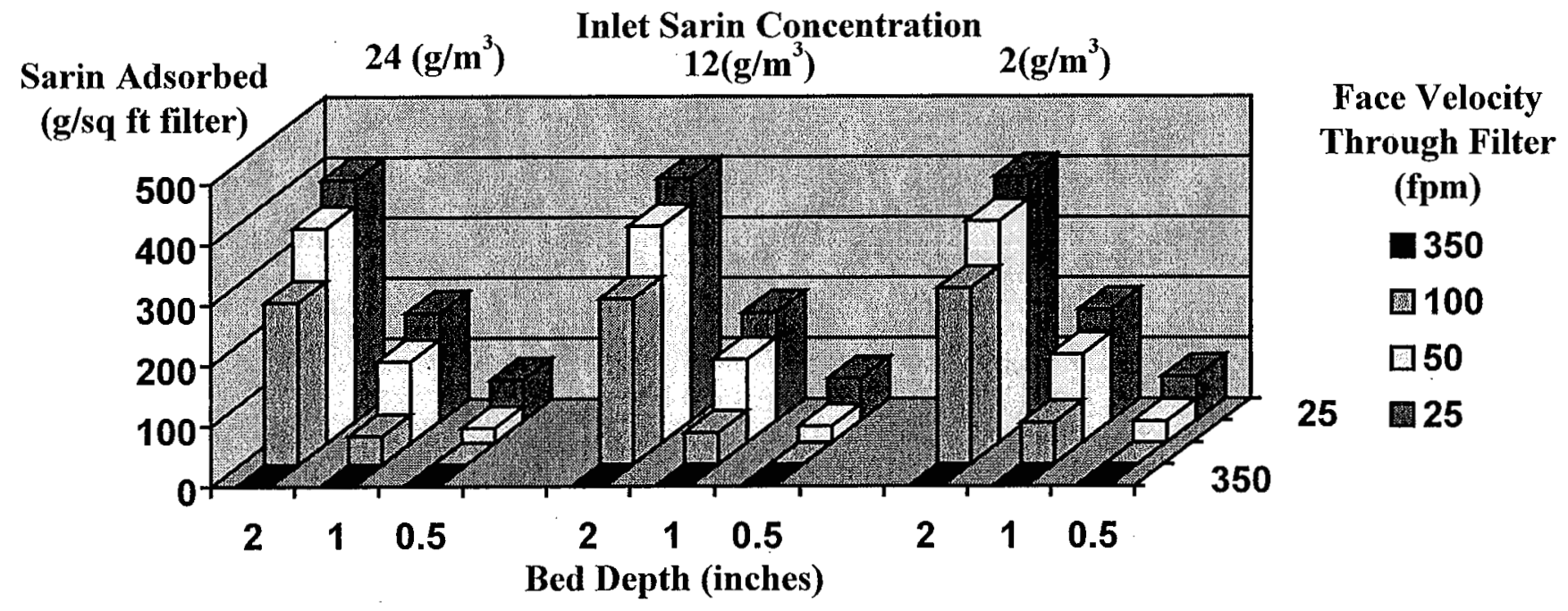

1 Assumes that the adsorptive capacity of the carbon meets the minimum acceptable capacity for impregnated military cartridges (DMMP) as estimated from Morrison and Campbell (1993). The difference between capacities as a function of mesh size calculated based on the work of Rehrmann and Jonas (1978). Calculations based on the data of (Holgate, et al. 1993), see appendix for calculation details. 
a half-inch deep filter adsorbs nothing before breakthrough since the mass transfer zone is longer than the carbon bed depth.

Potential degradation of carbon effectiveness during extended exposure to ambient air is an area needing more research. However, extrapolation from data for other organics does not indicate that significant degradation of capacity will occur. Weschler et al. (1993) tested the performance of 1" deep carbon beds for the removal of six different volatile organic compounds at ambient concentrations. They found no significant degradation of carbon filter performance over 18 months of continuous operation. Basic adsorption principles also suggest degradation will be minimal. Since the trace organic compounds in ambient air are typically more volatile than the agents of interest and would be found at lower concentrations, chemical agents entering the carbon bed at attack concentrations should preferentially adsorb onto the carbon (meaning that adsorption sites that are unavailable to more volatile compounds will left available for agent adsorption) and should displace any ambient organics adsorbed on the carbon. A potentially confounding factor is high relative humidities which are known to temporarily reduce capacity due to water condensation on carbon surfaces. Nelson and Correia (1976) reported that breakthrough times at 80 to $90 \%$ relative humidity were about $50 \%$ lower than when the relative humidity was $50 \%$ or less.

For chemical agents removed by the impregnation materials on the carbon, there is less information regarding capacities, adsorption rates, effectiveness after long exposures to ambient air, and confounding factors. Extrapolation from U.S. Army purchasing requirements for impregnated carbon (U.S. Army, 1992) suggests that the required adsorption capacity (total mass adsorbed before breakthrough) for carbonyl chloride is similar to that for the nerve agent surrogate used in testing (DMMP - dimethyl methylphosphonate). Required adsorption capacities for hydrogen cyanide and cyanogen chloride are about $20 \%$ and $35 \%$, respectively, of those for DMMP. These proportions should give a general indication of the amount of material adsorbed by the impregnation materials for a given system.

It is important to remember that the data in this paper assume the use of a highly adsorptive impregnated carbon, such as that used in military respirators. With lower capacity carbon, the time to breakthrough may be unacceptably shortened. Therefore, care must be taken to ensure that an appropriate carbon is used. In addition to carbon adsorption capacity, leakage past and through the filter is a critical factor. As was true with the particle filters, any air that leaks past the filter will go untreated. It is essential that the carbon filtration system be sealed and tested for filter bypass leakage to assure acceptable performance.

\section{PROTECTION SYSTEM DESIGN}

Since chemical and biological agents may be dispersed as gases, vapors, droplets, and/or solid particles, an ideal chemical/biological agent protection system must provide for removal of both particles and gases. The most effective location for an agent removal system is upstream of the supply fan. At this location, the duct is under negative pressure so duct leaks do not force untreated air into the building space. A single system could be placed in a duct which carries both the outdoor "fresh" air supply and the recirculated air return so that both indoor and outdoor 
releases would be treated before air is dispersed throughout the building. This air mixing would reduce the concentration in the system due to either an outdoor or an indoor release. However, this duct region is often poorly mixed, which may reduce filter effectiveness. Alternatively, two systems could be used: one in the return duct to reduce spreading of indoor releases and one in the fresh air supply duct to treat outdoor releases.

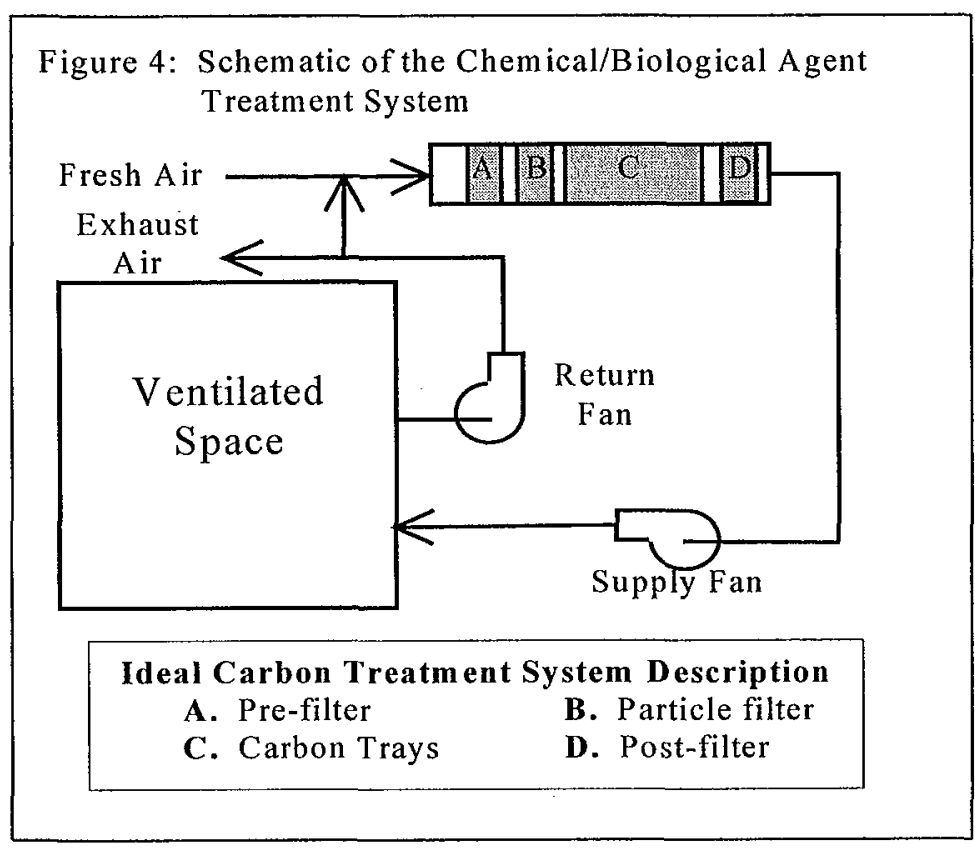

The ideal system, shown in Figure 4, would include (A) a coarse pre-filter to remove larger particles and reduce plugging of the particle filter, (B) a high quality particle filter placed before the carbon unit to prevent carbon filter plugging and assure that agent droplets and particles do not penetrate through the carbon filter, (C) one or more carbon filter units to remove agent vapors, and (D) a post system particle filter to remove any agent-contaminated carbon dust shed by the carbon bed.

To be most effective for outdoor releases, the ventilation system would need to be operated in a manner that creates a positive pressure within the building. Positive pressurization can be achieved either through differential flow (setting the supply air rate higher than the return air rate) or differential pressure (using a differential pressure gauge between the interior and exterior to control supply and return flows). Pressurization can drastically reduce the entry of agent by wind- and buoyancy-driven air infiltration through cracks in the building envelope. Nagada, et al. (1991) and Grot and Persily (1986) studied air infiltration into office buildings. They found that for low mechanical ventilation rates, infiltration through the building envelope could be similar in magnitude to mechanical ventilation. This means that in a building without pressurization, an HVAC treatment system that is $100 \%$ efficient at removing chemical and biological agents may reduce indoor concentrations (over an unprotected building) as little as $50 \%$ under some operating conditions. In buildings where positive pressurization is not possible, it is important to consider infiltration and HVAC operation modes in the treatment system and protection factor analysis. If a significant fraction of the air enters through infiltration this can be the dominant agent penetration route for both particles and gases.

The primary difficulties with installing this ideal protection system are providing adequate flow for building pressurization, accommodating the additional pressure drop through the treatment system, finding available space for locating the carbon units, and increased capital and energy costs. In some buildings, additional ventilation system capacity can be obtained by sealing the ductwork to prevent air leakage. Sealing duct leaks will also reduce the flow through the HVAC system required to maintain thermal comfort, which will reduce the pressure drop through the 
filters. Depending on the size and location of the leaks, sealing may also be important for minimizing transport of untreated air within the building.

It is possible to provide a system that will require a less substantial pressure drop by removing some components and/or reducing the carbon filter bed depth. Although a reduced system will provide less protection than the ideal system, it could make it possible to provide some chemical and biological agent protection in ventilation systems that cannot accommodate a more extensive treatment system.

\section{PRESSURE DROP}

Since installing an agent protection system increases the pressure drop through the HVAC system, the maximum available pressure drop can be the limiting factor for system design. However, even where a pressure drop problem does exist, it may be possible to retrofit the system using duct sealing along with new fans and motors to achieve the required pressure and flow.

The pressure drop required by a treatment system can be estimated by adding the pressure drops through the individual system components. For the ideal system, this means adding pressure drops for a coarse pre-filter, a high grade particle filter, a carbon adsorption bed, and a post-bed filter. The overall pressure drop through the HVAC system would be found by adding the pressure drop through the CB agent treatment system to the pressure drop from other HVAC system components such as ductwork and coils.

There are a wide range of particle filters which could be used. In general, filters with higher particle removal efficiencies have higher pressure drops. However, the amount of filter surface area, pleating, and filter design will also have a significant impact on the pressure drop. For the most protective systems, commercial HEPA box filters are available with a 0.16 " water initial resistance at a face velocity of $100 \mathrm{fpm}$ and 1 " drop at $500 \mathrm{fpm}$. The pressure drop required by the pre- and post-bed filters can be reduced substantially by using an 85\% ASHRAE dust spot filter, with an initial resistance of about 0.5 " water at $500 \mathrm{fpm}$, in place of the HEPA filter. Although these filters remove only about $50 \%$ of submicron particles, they remove about $85 \%$ of $1 \mu \mathrm{m}$ particles and almost $100 \%$ of particles larger than a few microns. Under most conditions, these filters would be sufficient to retain chemical agent droplets, chemical agent powders, bioaerosols (such as anthrax spores), and shed carbon particles.

The pressure drop through the carbon filter will depend on the air velocity through the filter, the bed depth, and the carbon grain size. Figure 5 shows the pressure drop through the carbon bed under several different conditions. This figure shows that the pressure drop for high bed velocities (above $100 \mathrm{fpm}$ for large grain carbon or above $50 \mathrm{fpm}$ for finer grain carbon) is much higher than can be supplied by a typical HVAC system. 


\section{DESIGN CASE STUDY}

As an example, we will design a chemical and biological agent treatment system for a ventilation system with a capacity of $25,000 \mathrm{cfm}$ and a main duct that is $6 \mathrm{ft}$ by $8 \mathrm{ft}$. This system would be typical for a medium sized commercial building (about 25,000 square feet) or a single zone within a larger building. For this ventilation system, the average velocity through the main duct is about $520 \mathrm{fpm}$. It is clear from Figures 3 and 5 that a velocity of $520 \mathrm{fpm}$ through the carbon bed would provide essentially no protection (since there is no removal at $350 \mathrm{fpm}$ and removal decreases with increasing velocity) and would require an unacceptably large pressure drop.

Figure 5: Pressure drop through a carbon bed (Rafson, 1988)

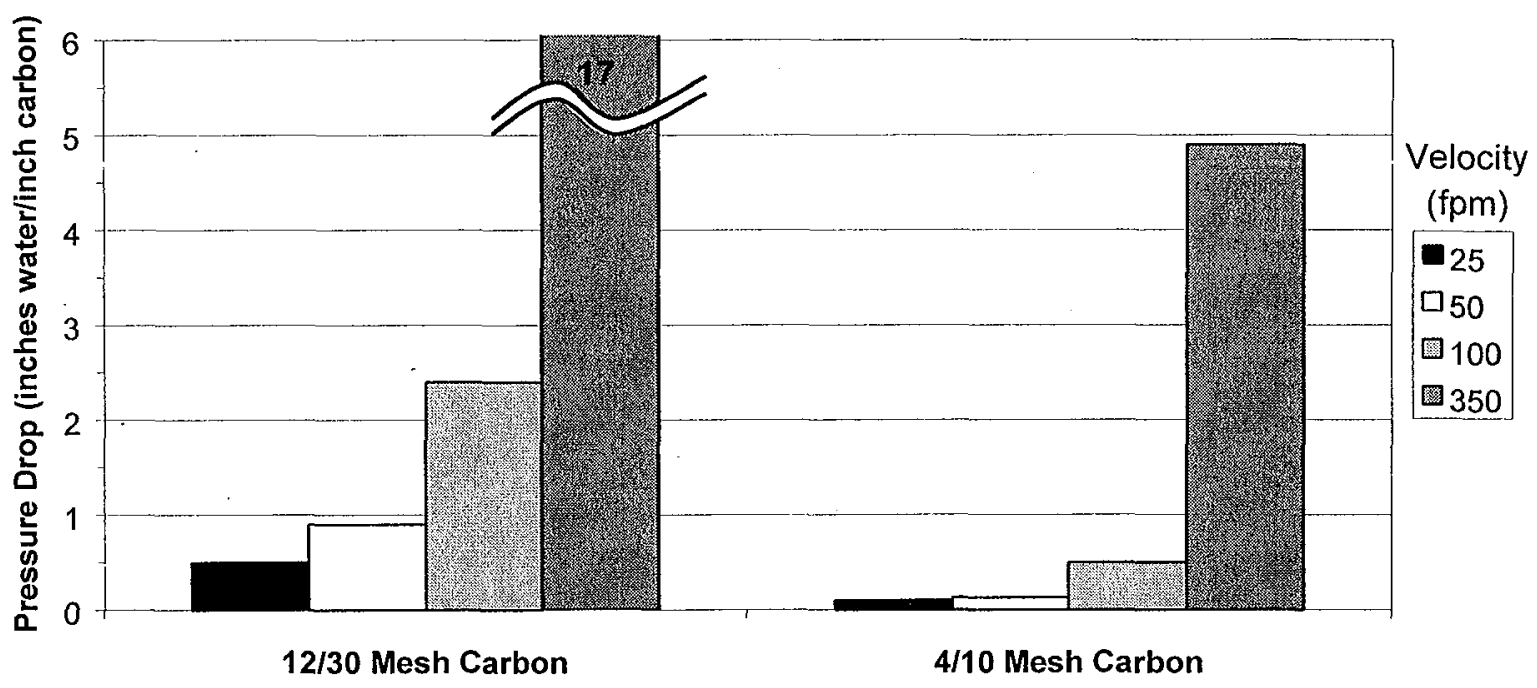

The smaller mesh size (12/30) corresponds to carbon grains between 0.6 and $1.4 \mathrm{~mm}$ and is typical of military respirator carbon. The larger mesh size $(4 / 10)$ corresponds to carbon grains between 1.6 and 4.7 mm.

Therefore, it will be necessary to slow the flow through the carbon filter. Simply placing the filters at a $45^{\circ}$ angle would increase the filter surface area and thereby reduce the flow through the filter to about $350 \mathrm{fpm}$. However, Figures 3 and 5 show that this is still unacceptable both in terms of protection and pressure drop. In order to be effective, the system needs a much larger filter surface area.

There are a number of ways that this increased surface area could be achieved. Two design options will be used to illustrate the process: (1) a multi-unit, 2 inch deep carbon adsorption bed system, similar to the type used in chemical agent disposal facilities and (2) 1" deep carbon filters placed in ' $V$ ' patterned, angled holders providing about 10 times the surface area of the duct cross section. 
Figure 6: Ten Tray Bank with 2" Carbon Beds. Ten of these units are required for the $25000 \mathrm{cfm}$ example system

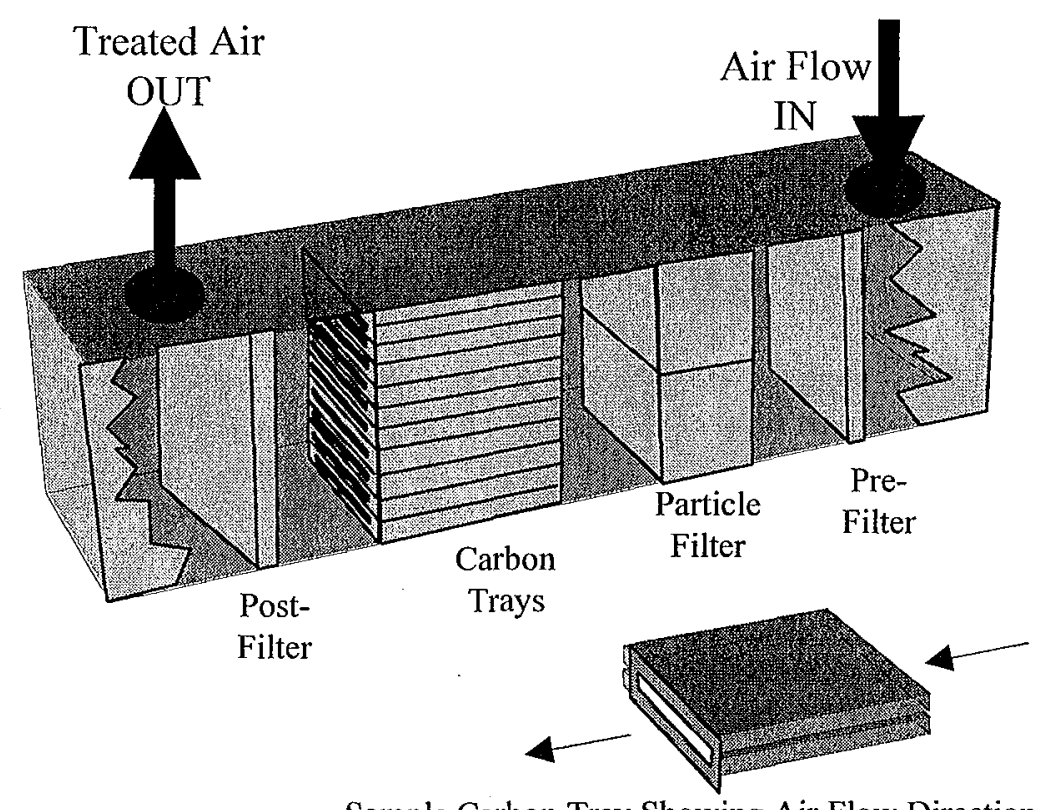

Sample Carbon Tray Showing Air Flow Direction

OPTION 1: Multi-Unit

Design

For the multi-unit system, the air flow is divided between several filtration units, each of which contains multiple carbon filter trays. An example of a single filter unit is shown in Figure 6. Each carbon tray within the unit is double-sided (24" by 30 "), with 2 " of carbon bed depth and 10 square feet of nominal filter area. To minimize pressure drop, we will design the system for a carbon bed face velocity

of $25 \mathrm{fpm}$. Therefore, each tray can handle $250 \mathrm{cfm}\left(25 \mathrm{fpm} \times 10 \mathrm{ft}^{2}\right.$ per filter $)$ and a total of 100 trays $(25,000 \mathrm{cfm} / 250 \mathrm{cfm})$ will be required. These trays could be arranged in filter bank units in any convenient arrangement, based on available space and layout: 4 banks with 25 trays each, 5 banks with 20 trays, etc. For illustration, this design will use 10 filter units, each with 10 carbon trays and a flowrate of $2500 \mathrm{cfm}$. Each unit would be tall enough to accommodate two 24" square HEPA filters stacked vertically. In this configuration, the face velocity through the HEPA filters is reduced to approximately $60 \%$ of the original duct velocity.

The total pressure drop for the filtration system is calculated as the sum of the drops through the pre-filter, HEPA filter, carbon filter, and post-filter. At $310 \mathrm{fpm}$ face velocity, a HEPA filter has an initial pressure drop of about 0.5 inches water. At $25 \mathrm{fpm}$, the pressure drop through the carbon bed would be 0.5 inches water/inch carbon for $12 / 30$ mesh carbon, or a total of 1 inch pressure drop for 2 " of carbon. Similarly, for $4 / 10$ mesh carbon the pressure drop would be 0.2 inches of water for 2 " carbon. The pre- and post-filters together would be expected to require about 0.1 inch water pressure drop. This gives an overall pressure drop of either 0.8 or 1.6 inches of water depending on which carbon grain size is used.

If a high grade non-HEPA filter was used (such as ASHRAE 85\% dust spot filters) instead of the HEPA filter, the pressure drop from the particle filter would be about 0.3 inches water. This reduces the system pressure drop to 0.6 inches of water for $4 / 10$ mesh carbon or 1.4 inches of water for $12 / 30$ mesh carbon. However in this configuration, there would be lower protection from submicron particles and droplets. There are many filters that could be used with 
efficiencies between $85 \%$ dust spot filters and HEPA filters. In general, the choice becomes a balance between pressure drop (and the accompanying problem of increased energy and capital costs) and filtration efficiency. The final decision will depend on the perceived risk and potential consequences of an attack for a specific building.

The adsorbent capacity of the various design options can be estimated from Figure 3 . The carbon system consists of 100 trays, each with $10 \mathrm{ft}^{2}$ of 2 " deep filter, so the total filter area is 1000 sq. $\mathrm{ft}$. For carbon with an adsorptive capacity similar to military grade respirator carbon, $12 / 30$ mesh size adsorbs about $400 \mathrm{~g} / \mathrm{sq}$. $\mathrm{ft}$ or $400 \mathrm{~kg}$ for the entire system. Similar carbon in $4 / 10$ mesh size will adsorb about $350 \mathrm{~g} / \mathrm{sq}$. $\mathrm{ft}$. or $350 \mathrm{~kg}$ for the entire system. The capacity of the system is approximately independent of the concentration of the agent in the ventilation air, as long as the length of the mass transfer zone does not approach the filter depth. The effect of mass transfer zone can be seen in Figure 3a. In general, the adsorption capacity for a given velocity and bed depth combination is essentially independent of agent concentration. However, for a 2 " deep bed at $100 \mathrm{fpm}$ the adsorption capacity for an inlet concentration of $2 \mathrm{~g} / \mathrm{m}^{3} \operatorname{sarin}$ is approximately $50 \%$ more than when the concentration is $24 \mathrm{~g} / \mathrm{m}^{3}$. This difference is due to the

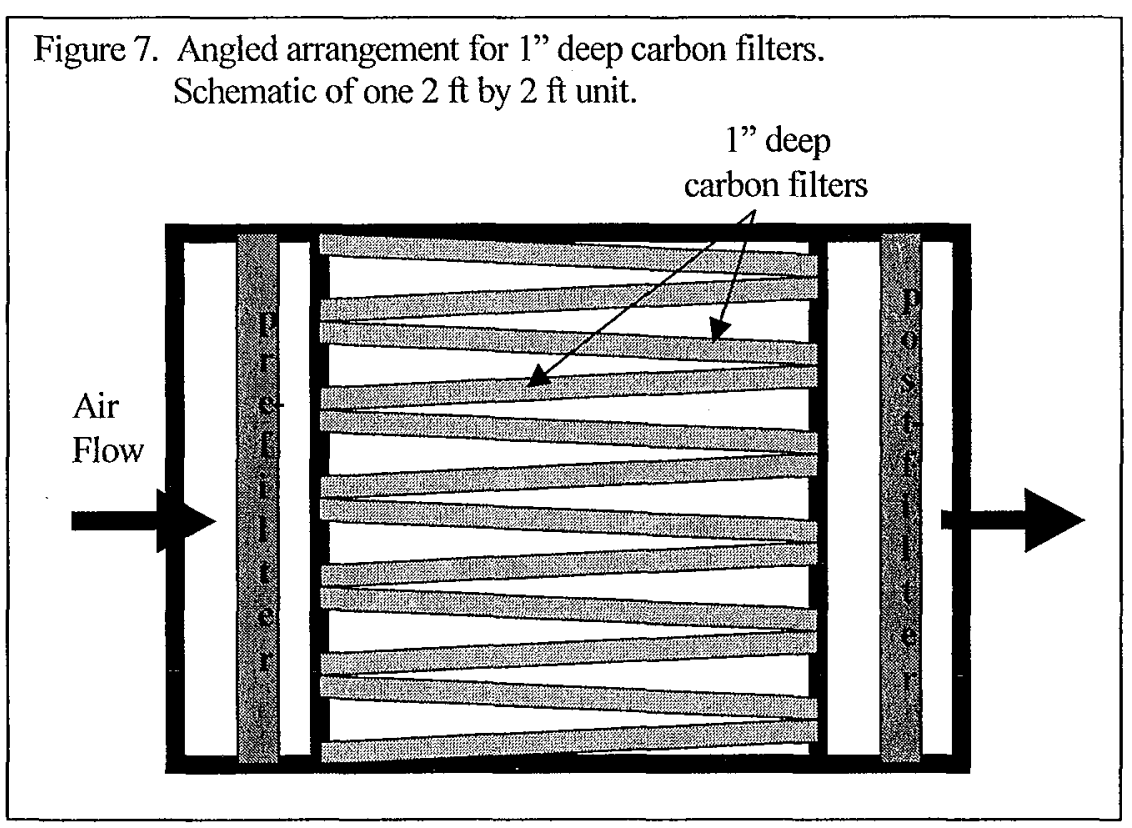
longer mass transfer zone produced by higher inlet concentrations.

OPTION 2: Pleated Filter Holder Design

A second design option consists of 1" deep carbon filters in a 'pleated' or angled holder, as shown in Figure 7 . The $2 \mathrm{ft}$ by $2 \mathrm{ft}$ holder units are stacked and installed directly in the ventilation duct. This system may be easier to install than the multi-tray

units in the previous design. This design provides a carbon filter area of about 10 times the duct flow area. In our example, this means that the face velocity through each carbon filter panel would be about $50 \mathrm{fpm}(500 \mathrm{fpm} / 10)$. Figure 5 shows that for 12/30 mesh carbon the pressure drop through the carbon bed would be 0.9 inches of water. The velocity through the HEPA filter would be about $500 \mathrm{fpm}$, with a corresponding pressure drop of about 1.0 inch water. Including the 0.1 inch initial resistance of the pre- and post- filters, the overall system pressure drop would be 2 inches of water if HEPA filters are used. The pressure drop could be reduced to about 1.5 inches of water if high grade particle filters were used. For 4/10 mesh carbon, the pressure drop through the carbon bed would be 0.1 inches. This would give an overall pressure drop of about 1.2 inches of water if HEPA filters were used or 0.7 inches of water if high grade particle filters were used. These pressure drops are all for clean filters and provisions should be made to handle some additional pressure drop as the filters become loaded with particles. 
Table 1. Design options for a sample HVAC system with a capacity of $25,000 \mathrm{cfm}$

\begin{tabular}{|c|l|c|c|}
\cline { 3 - 4 } & Multi-Tray System & Angled Filter System \\
\hline & Depth of Carbon Bed (inches) & 2 & 1 \\
$12 / 30$ & Tolocity Through Carbon Bed (fpm) & 25 & 50 \\
Mesh & Pressure Drop w/ HEPA filters (inch $\left.\mathrm{H}_{2} \mathrm{O}\right)$ & 400 & 65 \\
Carbon & Pressure Drop w/ 85\% filters (inch $\left.\mathrm{H}_{2} \mathrm{O}\right)$ & 3.0 & 2.9 \\
& & 1.5 & 1.4 \\
\hline $4 / 10$ & Total Sarin Adsorbed (kg) & 350 & 25 \\
Mesh & Pressure Drop w/ HEPA filters (inch $\left.\mathrm{H}_{2} \mathrm{O}\right)$ & 2.2 & 2.1 \\
Carbon & Pressure Drop w/ 85\% filters (inch $\left.\mathrm{H}_{2} \mathrm{O}\right)$ & 0.7 & 0.6 \\
\hline
\end{tabular}

Using Figure 3, the amount of agent (sarin) which could be adsorbed can be estimated. The overall carbon filter area is about 10 times the duct area or $480 \mathrm{sq}$. ft. $(10 \times 48 \mathrm{sq}$. ft.). For 12/30 mesh carbon, the total amount adsorbed would be $135 \mathrm{~g} / \mathrm{sq}$. $\mathrm{ft}$. or $65 \mathrm{~kg}$ for all the carbon filters. For $4 / 10$ mesh carbon, the total amount adsorbed would be $47 \mathrm{~g} / \mathrm{sq}$. ft. or $23 \mathrm{~kg}$. Table 1 summarizes the results of the sample calculation for the two system designs.

These examples illustrate just two possible system design configurations. Many other options could be explored for reducing the system pressure drop and/or improving adsorption capacity, depending on the particular arrangement of the ventilation ducting where the treatment system is to be installed. For instance, in some cases it may be possible to angle the particle filters, buy filters with more pleating and a lower pressure drop, or place the filters in "pleated" holders to reduce the velocity, and therefore pressure drop, through the filters. Alternatively, it may be possible to increase the size of the duct in the region of the carbon filter banks, if there is adequate available space. This would both increase the adsorption of the system and reduce the pressure drop. In our example, if the duct were increased from $6 \mathrm{ft}$ by $8 \mathrm{ft}$ to $10 \mathrm{ft}$ by $10 \mathrm{ft}$, the velocity in the duct would be approximately halved. For the in duct filtration system described in the example system, this would not only reduce the pressure drop through the carbon and particle filters, but would also increase the total carbon available for adsorption and therefore increase system adsorption capacity. Increasing the duct size could result in a substantial reduction in overall pressure requirements, particularly in the case where HEPA filters are used.

\section{SUMMARY AND CONCLUSIONS}

In the event of a chemical or biological attack, there may not be adequate time for evacuation, particularly in densely populated areas. This could leave sheltering in place as the only viable option for protecting building inhabitants. For sensitive buildings and areas, a building protection system would provide an additional level of security for occupants and reduce the 
potential for injuries and deaths. As a side benefit, the system may also reduce the levels of common air contaminants and allergens and potentially improve the health and comfort of occupants.

It is possible to install an effective chemical/biological agent protection system in many existing air handling systems, although some modifications would almost certainly be required. An ideal protection system consists of both fiber filters for removing particles and carbon filters for removing gases and vapors. Fiber filters have a long history of use in buildings and their operation and maintenance requirements are well known. Carbon filters are less common in building HVAC systems and there are still some questions regarding long term operation and maintenance requirements. The primary system needs are adequate airflow rate for building pressurization, sufficient pressure drop to accommodate the treatment system, and an installation location which can accommodate the additional equipment required. Operation of the system is not inexpensive and will require both capital costs for system installation and ongoing costs for maintenance and increased power consumption.

The adsorption capacity of the system will depend primarily on the system design, the amount and capacity of carbon used, and the type of chemical agent vapor encountered. For the two treatment system designs for a $25,000 \mathrm{cfm}$ ventilation system, pressure drops ranged between 0.6 and 2 inches of water. The systems had the capacity to adsorb between 37 and $425 \mathrm{~kg}$ sarin before the concentration of sarin leaving the filter reached a level which was unhealthy to breathe.

While it is possible to design a system which will be effective against almost any conceivable release scenario, in most cases this will be impractical. As the level of protection, in terms of particle removal efficiency and gas adsorption capacity, is increased, the cost of installing and operating the system also increases. In general, decisions regarding the most appropriate level of protection for a given building will be based on an analysis of the probability of attack and the probable consequences if an attack occurred. This risk analysis then needs to be balanced against issues such as costs and availability of space for retrofitting.

\section{REFERENCES}

ASHRAE (1992): Gravimetric and dust-spot procedures for testing air-cleaning devices used in general ventilation for removing particulate matter, Atlanta, GA American Society for Heating, Refrigeration, and Air-Conditioning Engineers, Inc. (Standard 52.1-1992).

Grot, R.A. and Persily, A.K.: Measured air infiltration and ventilation rates in eight large office buildings. Measured Air Leakage of Buildings. ASTM STP 904, H.R. Trechsel and P.L. Lagus, Eds., American Society for Testing Materials, Philadelphia, 1986, pp. 151-183.

Hanley, J.T., Ensor, D.S., Smith, D.D., and Sparks, L.E.: Fractional aerosol filtration efficiency of in-duct ventilation air cleaners. Indoor Air 4, pp. 169-178, 1994. 
Holgate, H.R., Scherer, L., and Talib, A.: Assessment of carbon filter system performance. MTR 93W0000034, MITRE, McLean, Virginia. June 1993.

Morrison, R.W. and Campbell L.E.: Evaluation of a chromium-free impregnated activated carbon as an adsorbent for chemical warfare agents. Edgewood Research, Development, \& Engineering Center. ERDEC-TR-11.0, October 1993.

Nagda, N.L., Koontz, M.D., and Albrecht, R.J.: Effect of ventilation rate in a healthy building. IAQ '91: Healthy Buildings, American Society of Heating, Refrigeration and AirConditioning Engineers, Washington, DC, pp101-107, 1991.

Nelson, G.O. and Correia, A.N.: Respirator cartridge efficiency studies: VIII. Summary and Conclusions. American Industrial Hygiene Association Journal, pp. 514-525, Sept 1976.

Rafson, H.J.: Odor and VOC Control Handbook. McGraw Hill, San Francisco. 1988.

Rehrmann, J.A. and Jonas, L.A.: Dependence of gas adsorption rates on carbon granule size and linear flow velocity. Carbon 16, pp. 47-51, 1978.

U.S. Army Edgewood Research, Development, and Engineering Center Purchase Description EA-C-1704: Carbon, activated, impregnated, copper-silver-zinc-molybdenumtriethylenediamine (ASZM-TEDA), 24 January 1992.

Weschler, C.J., Shields, H.C., and Naik, D.V.: An evaluation of activated carbon filters for the control of ozone, sulfur dioxide, and selected volatile organic compounds. IAQ 92:

Environments for People, American Society of Heating, Refrigeration and Air-Conditioning Engineers, Atlanta, pp. 233-240, 1993. 


\section{APPENDIX}

The time to breakthrough for the carbon bed was calculated using the Mecklenburg equation in the form:

where

$$
t_{b}=\frac{\rho_{b} W_{e}}{V_{L} C_{o}}\left[\lambda-\lambda_{c}\right]
$$

$\mathrm{t}_{\mathrm{b}}=$ time to breakthrough (s)

$\rho_{\mathrm{b}}=$ bulk (apparent) density of the carbon $\left(\mathrm{g} / \mathrm{cm}^{3}\right)$

$\mathrm{W}_{\mathrm{e}}=$ equilibrium carbon capacity from isotherm data $(\mathrm{g} / \mathrm{g})$

$V_{L}=$ linear (superficial) velocity of air through the carbon bed $(\mathrm{cm} / \mathrm{s}$ )

$\mathrm{C}_{\mathrm{o}}=$ challenge concentration of agent $\left(\mathrm{g} / \mathrm{cm}^{3}\right)$

$\lambda=$ depth of carbon bed $(\mathrm{cm})$

$\lambda_{\mathrm{c}}=$ critical bed depth (width of mass transfer zone) $(\mathrm{cm})$

The critical bed depth can be defined as:

$$
\lambda_{c}=\frac{V_{L}}{k_{v}} \ln \frac{C_{o}}{C_{b}}
$$

where

$k_{v}=$ first order adsorption rate constant $(/ \mathrm{min})$

$C_{b}=$ filter exit concentration at breakthrough $\left(\mathrm{g} / \mathrm{cm}^{3}\right)$

This definition is consistent with a first order adsorption process. The combination of equations 1 and 2 is equivalent to the Wheeler equation for carbon adsorption processes.

For the calculations in Figure 3, the following values were used for the constants in equations 1 and 2:

$$
\begin{aligned}
& \rho_{\mathrm{b}}=0.68 \mathrm{~g} / \mathrm{cm}^{3} \\
& \mathrm{~W}_{\mathrm{e}}=0.14 \mathrm{~g} / \mathrm{g} \\
& k_{v}=250 / \mathrm{sec}(4 / 10 \mathrm{mesh}), 500 / \mathrm{sec}(12 / 30 \mathrm{mesh}) \\
& C_{b}=1 \times 10^{-13} \mathrm{~g} / \mathrm{cm}^{3}
\end{aligned}
$$




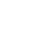

